\title{
Role of Corpus Callosum in Global Developmental Delay
}

\author{
K Mounisha ${ }^{\circledR 1}$, MU Jeevika ${ }^{2}$, BG Mahesh ${ }^{11}$, B Adarsh ${ }^{\oplus 1}$, KK Nirnay ${ }^{\circledR 1}$ \\ ${ }^{1}$ Post Graduate, Department of Radiology, JJM Medical College, Davangere, Karnataka, India, ${ }^{2}$ Professor \& HOD, Department of Radiology, JJM Medical College, \\ Davanagere, Karnataka, India.
}

\section{Abstract}

Background: Neuroimaging provides essential information as evidence of previous injuries, specific abnormalities that could indicate a group or a particular disease in babies with global developmental delay. The objectives is to assess the difference of corpus callosal size in various regions of the corpus callosum in cases of children with developmental delay and to know the etiology using MRI. Subjects and Methods: My study includes 102 children between 1 to 6 years of age among which 51 children are cases having signs and symptoms of developmental delay and 51 children are controls i.e. healthy babies. They underwent MRI in the Department of Radiology, JJM Medical College, Davangere in whom corpus callosum is imaged on sagittal MR sections and its size is calculated in different regions. Results: Abnormalities of the corpus callosum like thinning and agenesis were observed in $55.5 \%(\mathrm{~N}=27)$ in the study group, and none of the patients in the control group. Partial corpus callosal agenesis was present in $3.9 \%$ of patients. Complete agenesis in $3.9 \%$ of patients. Thinning of the corpus callosum was seen in $45 \%$ of patients who were in the study group. Conclusion: The current study suggests that corpus callosal abnormalities, including brain changes, is useful in knowing the etiology of global developmental delay.

Keywords: Corpus callosum, Developmental delay, MRI brain.

Corresponding Author: K Mounisha, Post Graduate, Department of Radiology, JJM Medical College, Davangere, Karnataka, India. E-mail: mounisha001@gmail.com

Received: 06 April 2020

\section{Introduction}

Neuroimaging provides essential information as evidence of previous injuries, specific abnormalities that could indicate a group or a particular disease in babies with global developmental delay.

The term Global Developmental Delay is commonly used by clinicians which means a significant delay in two or more of the four main developmental domains. It is significant when there is a deficit in performance of at least 2SD below the age-appropriate mean on accepted standardized assessment tests. ${ }^{[1]}$

GDD is a common disease that affects $1 \%$ to $3 \%$ of children under five years. ${ }^{[2]}$

MRI is a handy tool in identifying corpus callosal abnormalities. The degree of development of the corpus callosum can be used as an indicator to determine the period of fetal growth where the insult has occurred. ${ }^{[3]}$

\section{Subjects and Methods}

\section{Source of Data}

This is a hospital-based case-control study which was conducted with a sample size of 102 children between 1 to 6 years of age, for a period of 1 year from June 2018 - June 2019, who had clinical signs and symptoms of developmental delay and who were referred to Department of Radiology, JJM Medical College, Davangere.

51 children for evaluation of developmental delay, were included as the cases and the control group included 51 children in whom developmental delay was ruled out.

Claustrophobic patients and patients with MRI incompatible implants are excluded from the study.

\section{Data Collection}

After obtaining written informed consent, a detailed history was taken, and a clinical examination was done. The findings were tabulated. Then the patients were evaluated by 1.5 tesla Philips (Achieva) MRI machine with the patients in the supine position.

The corpus callosal size was measured in the following areas of the corpus callosum on MRI-

Rostrum, Genu, Rostral body, anterior mid-body, Posterior mid-body, Isthmus, Splenium. 
Subdivisions of the corpus callosum as per the Witelson's method: I — Rostrum; II — Genu; III — Rostral body; IV Anterior mid-body; V - Posterior mid-body; VI — Isthmus; VII - Splenium.

\section{Statistical Analysis}
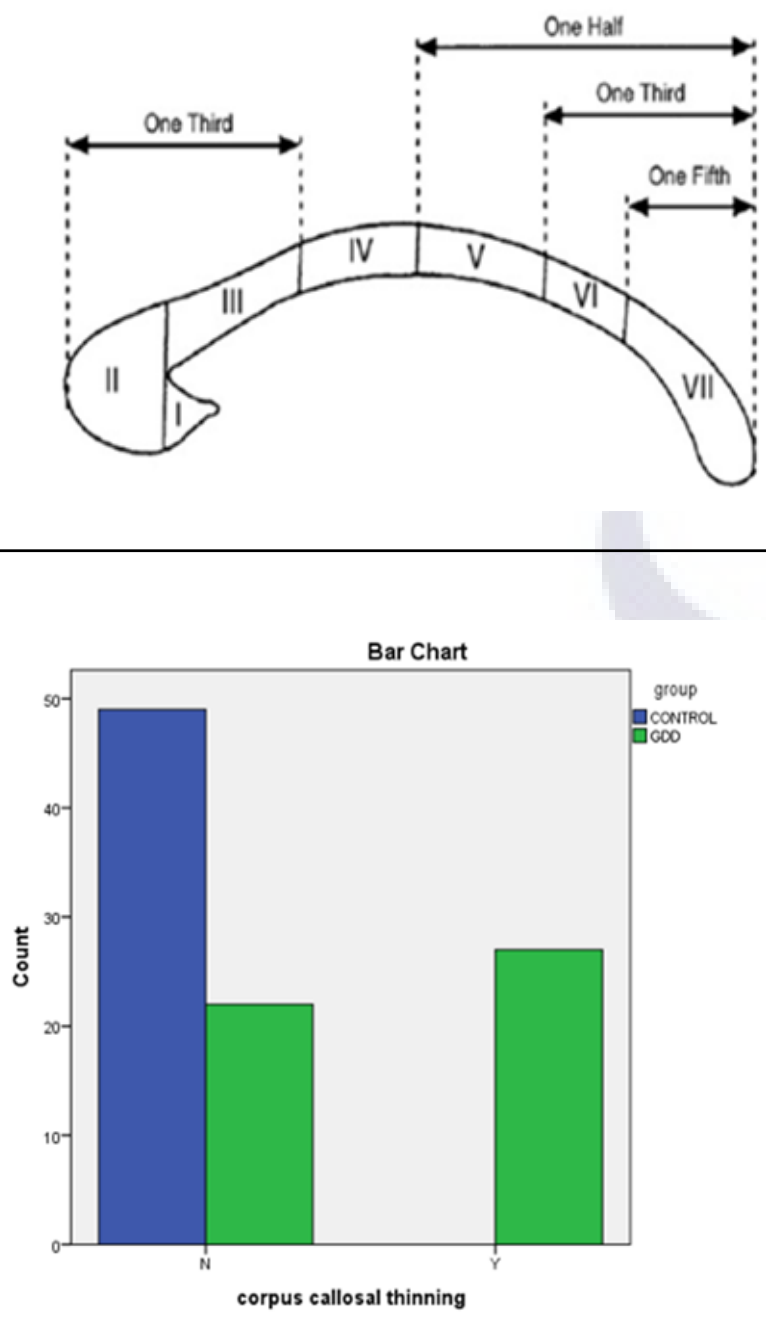

Figure 1: Bar chart depicting the distribution of corpuscallosal thinning /agenesis in control and case group ( $\mathrm{N}=$ absent, $\mathrm{Y}=$ present $)$

\section{Results}

The mean age of children in cases was 5.1 years, and in controls, the mean age was 5.5 years.

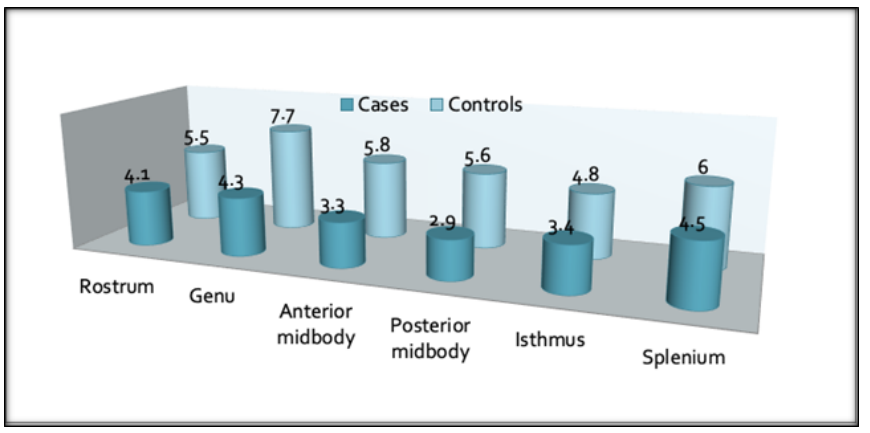

Figure 2: Summaryof mean values of corpus callosum
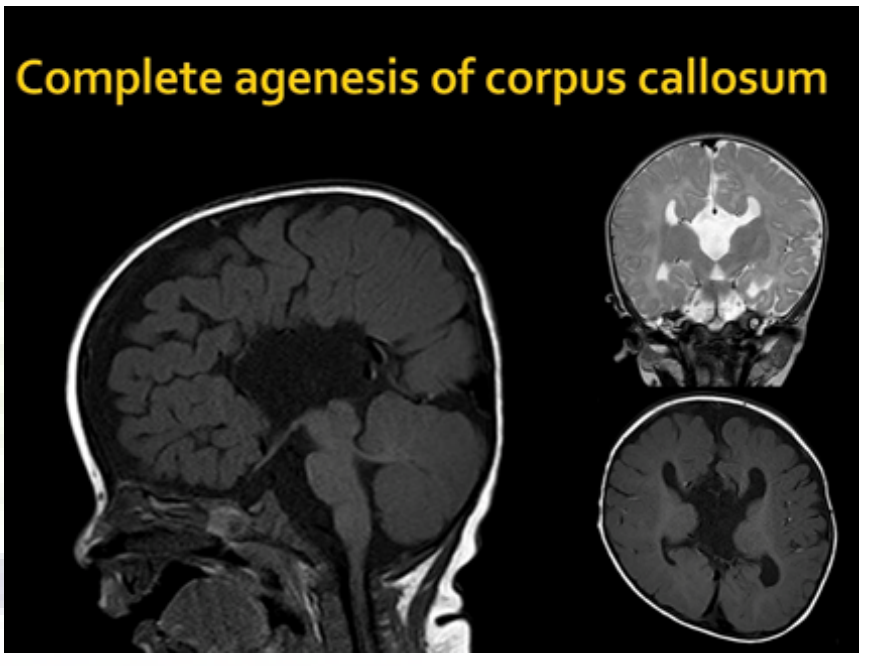

Figure 3: Complete Agenesis of Corpus Callosum

Abnormalities of the corpus callosum like thinning and agenesis were observed in $55.5 \%(\mathrm{~N}=27)$ in the study group and none of the children in the control group.

Partial corpus callosal agenesis was present in 3.9\% of children, complete agenesis in $3.9 \%$ patients and thinning of the corpus callosum in $45 \%$ of children who were in the study group. [Figure 1]

\section{Discussion}

The corpus callosum, in Latin which means "tough body" is the most giant bundle of association fibers with a population of about 200 million axons. The corpus callosum (CC) is a bundle of nerve fibers that connects the left and right hemispheres of the brain. It is the most extensive neural pathway that connects the two homologous cortical areas. The most anterior part is the genu, which connects the prefrontal cortices on either side. 


\section{Partial agenesis of corpus callosum}

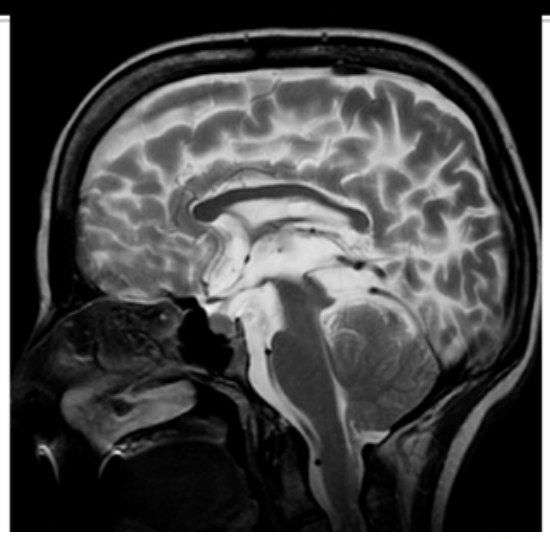

Figure 4: Partial Agenesis of Corpus Callosum
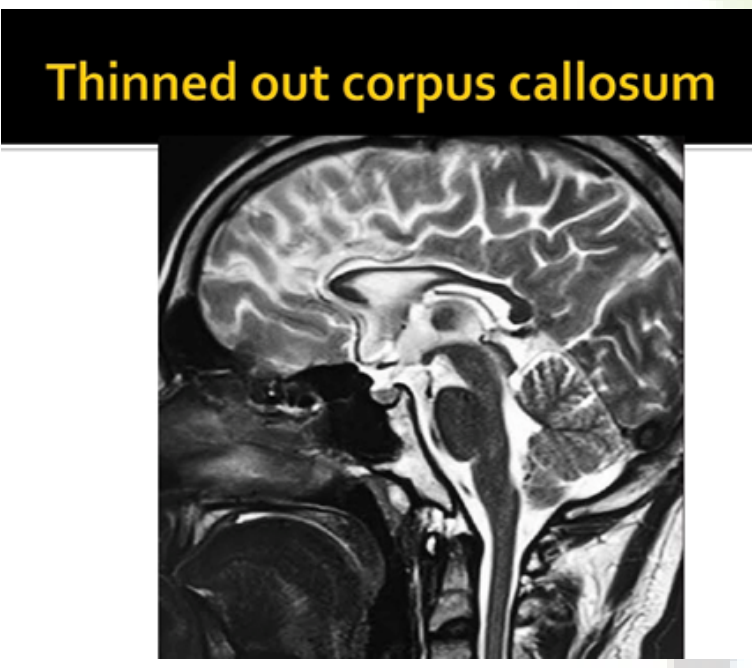

Figure 5: Thinned Out Corpus Callosum

The middle portions connect the motor and somatosensory regions. The caudal part of the body connects the cortex from the temporoparietooccipital junction. The splenium also connects the dorsal parietal and occipital regions. ${ }^{[4]}$

Its function is to connect the two cerebral hemispheres. The absence or thinning of these axons causes reduced interconnectivity of cortical processing areas. This leads to a limited capacity of cortical net-works required to process information leading to developmental delay in children with dysgenesis and agenesis of the corpus callosum.

Treatment should be started promptly to prevent the adverse complications of this disorder like social exclusion and to utilize central nervous system plasticity as much as possible.
Partial corpus callosal agenesis [Figure 4] was present in 3.9\% $(\mathrm{N}=2)$ children, and complete agenesis of the $\mathrm{CC}$ was seen in $3.9 \%(\mathrm{~N}=2)$ children, thinning of the corpus callosum was seen in $45 \%(\mathrm{~N}=27)$ of children who were in the study group.

$12 \%(\mathrm{~N}=6)$ of the children in our study group had a reduction in the size of the rostrum of the corpus callosum.

$31 \%(\mathrm{~N}=16)$ children with developmental delay had reduced the size of the body of corpus callosum.

$17 \%(\mathrm{~N}=9)$ children with developmental delay had a reduced size of the isthmus.

$15 \%(\mathrm{~N}=8)$ children in our study group had a reduced size of the splenium of the corpus callosum. [Figure 4]

Diffuse thinning of the corpus callosum was seen in HIE. [Figure 5]

The posterior part of corpus callosal thinning was seen in hypoglycemia.

Colpocephaly was seen in partial dysgenesis of the corpus callosum.

Complete agenesis of the corpus callosum [Figure 3] seemed to have syndrome associations like Arnold Chiari malformation, Dandy-Walker syndrome, Aicardi's syndrome. ${ }^{[1]}$

\section{Conclusion}

Corpus colossal abnormalities, including other brain changes, are useful in knowing the etiology of global developmental delay.

Good knowledge of the factors causing abnormal corpus callosal development in a specific pattern for an individual patient can lead to better clinical correlation and genetic counseling.

\section{References}

1. Ali AS, Syed NP, Murthy GSN, Nori M, Abkari A, Pooja $\mathrm{BK}$, et al. Magnetic Resonance Imaging (MRI) Evaluation of Developmental Delay in Pediatric Patients by. J Clin Diagn Res. 2015;9(1):21-24. Available from: https://dx.doi.org/10.7860/ JCDR/2015/11921.5478.

2. Momen AA, Jelodar G, Dehdashti H. Brain Magnetic Resonance Imaging Findings in Developmentally Delayed Children. Int J Ped. 2011;2011:1-4. Available from: https://dx.doi.org/10. $1155 / 2011 / 386984$.

3. Cascio C, Styner M, Smith RG, Poe MD, Gerig G, Hazlett $\mathrm{HC}$, et al. Reduced Relationship to Cortical White Matter Volume Revealed by Tractography-Based Segmentation of the Corpus Callosum in Young Children With Developmental Delay by Carissa Cascio. Am J Psychiatry. 2006;163:2157-2163. Available from: https://doi.org/10.1176/ajp.2006.163.12.2157. 
4. Park SE, Choi DS, Shin HS, Baek HJ, Choi HC, Kim JE. Splenial Lesions of the Corpus Callosum: Disease Spectrum and MRI Findings. Korean J Radiol. 2017;18(4):710-721. Available from: https://dx.doi.org/10.3348/kjr.2017.18.4.710.

Copyright: (C) the author(s), 2020. It is an open-access article distributed under the terms of the Creative Commons Attribution License (CC BY 4.0), which permits authors to retain ownership of the copyright for their content, and allow anyone to download, reuse, reprint, modify, distribute and/or copy the content as long as the original authors and source are cited.

How to cite this article: Mounisha K, Jeevika MU, Mahesh BG, Adarsh B, Nirnay KK. Role of Corpus Callosum in Global Developmental Delay. Asian J. Med. Radiol. Res. 2020;8(1):128131.

DOI: dx.doi.org/10.47009/ajmrr.2020.8.1.23

Source of Support: Nil, Conflict of Interest: None declared. 